\title{
25 ANOS DE FOTOETNOGRAFIA: BALANÇO, DESAFIOS E PERSPECTIVAS
}

\section{5 years of photoetnography: balance, challenges and perspectives}

Fábio Lopes Alves ${ }^{1}$

Claudia Barcelos de Moura Abreu.2

Tania Maria Rechia Schroeder ${ }^{3}$

Luzia Batista de Oliveira e Silva ${ }^{4}$

http://dx.doi.org/10.52641/cadcaj.v7i1.648

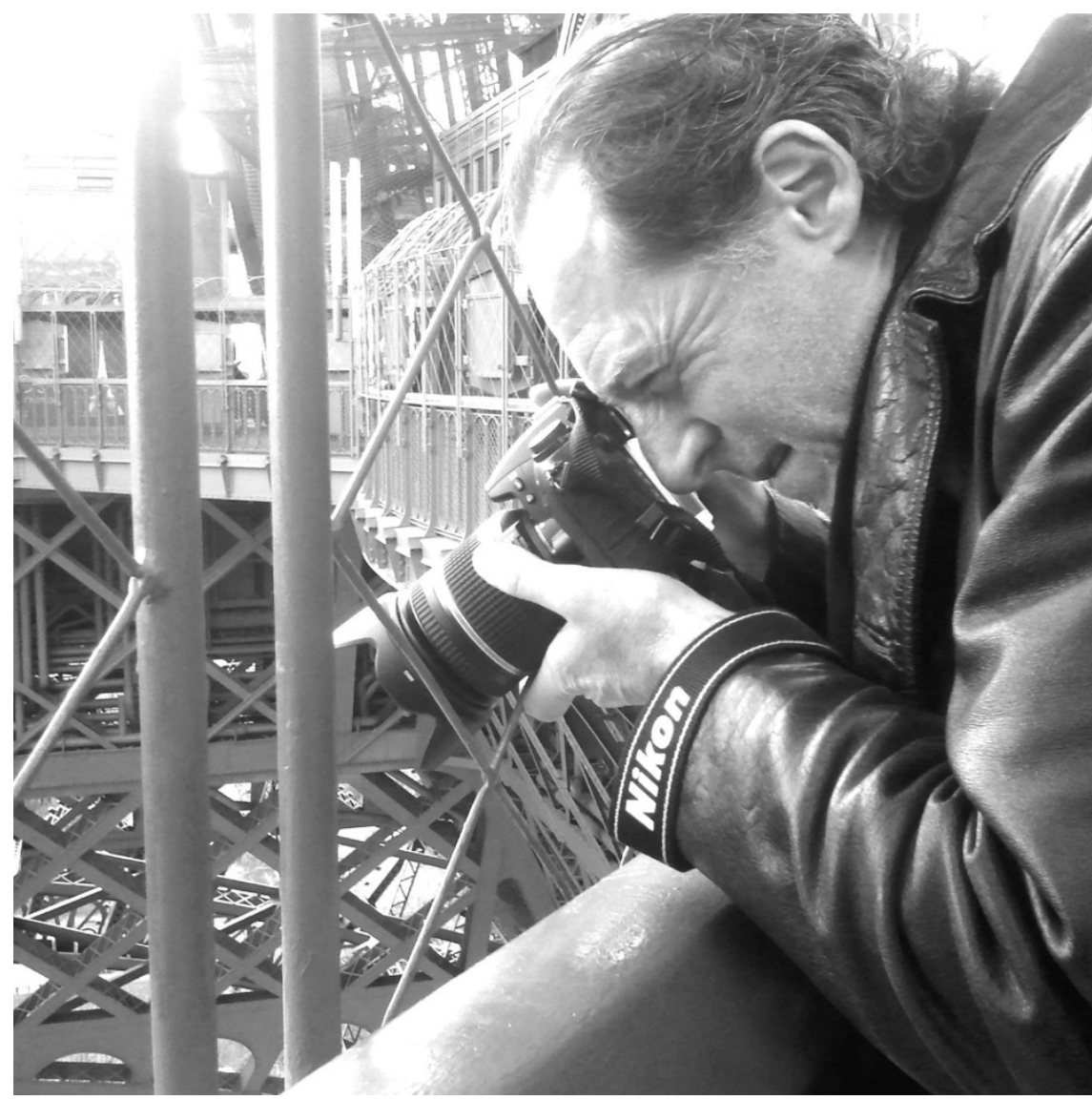

Foto: Katia Arruda, 2013

\footnotetext{
${ }^{1}$ Professor do Programa de Pós-Graduação em Sociedade, Cultura e Fronteiras da Universidade Estadual do Oeste do Paraná. https://orcid.org/0000-0002-2114-3831

2 Professora do Programa de Pós-Graduação em Educação da Universidade Federal de São Paulo. https://orcid.org/0000-0001-8814-1235

3 Professora do Programa de Pós-Graduação em Educação da Universidade Estadual do Oeste do Paraná. https://orcid.org/0000-0002-3646-3088

${ }^{4}$ Pós-doutorado, Faculdade de Filosofia da Universidade de Borgonha - Dijon/França. https://orcid.org/0000$\underline{0003-4880-7199}$
} 
É com imensa consternação que apresentamos o presente dossiê. Infelizmente, quando esse número era organizado, por complicações da COVID-19, o prof. Mauro Guilherme Pinheiro Koury, editor-chefe da Revista Brasileira de Sociologia da Emoção - RBSE faleceu. Juntamente com os organizadores, trabalhou arduamente para que esse dossiê se concretizasse. Herdeiro da tradição sociológica de Georg Simmel, após retornar da Universidade de Glasgow, Escócia, ingressou como professor da Universidade Federal da Paraíba. Koury é daqueles intelectuais que o leitor sabia, de antemão, onde encontrá-lo; bastava ir aos encontros da Associação Brasileira de Antropologia, Associação Brasileira de Ciências Sociais, Reuniões de Antropologia do Mercosul, Associação Latino-Americana de Sociologia, além de outros eventos da área e logo se perceberia sua assiduidade. Não por acaso, Koury foi o fundador da RBSE e da Revista de Antropologia e Sociologia - Sociabilidades Urbanas (SOCURBS), foi coordenador do Grupo de Pesquisa em Antropologia e Sociologia das Emoções (GREM) e Grupo Interdisciplinar de Estudos em Imagem (GREI), assim como desbravador, no Brasil, daquilo que conhecemos por sociologia e antropologia das emoções. Koury foi quem assumiu a responsabilidade de introduzir nas universidades brasileiras uma parte significativa dos clássicos que lemos, em português, na medida em que traduziu e publicou na RBSE textos de autores como Marcel Mauss, Georg Simmel, Robert Park, Maurice Halbwachs e Eric Hobsbawn que, por falta de tradução, até então eram desconhecidos por parte do público brasileiro. Koury formou uma importante geração de intelectuais no campo das Ciências Sociais, em especial da Sociologia e Antropologia.

Esse momento de tristeza coincide com o aniversário de 25 anos da fotoetnografia, razão pela qual o presente dossiê reúne contribuições de diversos autores que problematizam de um lado, os usos e aplicações do conceito achuttiano no âmbito das pesquisas em Ciências Humanas e Sociais e, de outro, a contribuição gerada pela consolidação dos estudos em imagens, no campo da Antropologia e Sociologia. Em 1996, Luiz Eduardo Robinson Achutti, sob orientação da antropóloga Ondina Fachel Leal, defendeu a dissertação de mestrado na Universidade Federal do Rio Grande do Sul-UFRGS, intitulada "Fotoetnografia: um trabalho de Antropologia visual sobre cotidiano, lixo e trabalho, em uma vila popular na cidade de Porto Alegre", posteriormente publicada na forma de livro pela Tomo Editorial. Naquele momento, a dissertação de Achutti apresentava três contribuições fundamentais ao campo da Antropologia Visual: a primeira foi o ineditismo. Afinal, o autor propôs um conceito antropológico, até então, inexistente. O segundo aspecto é que, com isso, inaugurou um novo campo no âmbito da antropologia visual; e o terceiro é que formulou, na dissertação de mestrado, de forma teórica e metodológica, os passos a serem seguidos por outras pesquisas fotoetnográficas. 
No ano de 2002, sob orientação do antropólogo francês Jean Arlaud, Achutti defendeu a tese de doutorado em Antropologia na Universidade de Paris VII Denis-Diderot, intitulada "Fotoetnografia da biblioteca Jardim", posteriormente publicada na forma de livro, na França pela editora Teraedre e, no Brasil, pela Tomo Editorial em coedição com a editora da UFRGS. Tanto a dissertação de mestrado, quanto a tese de doutorado de Achutti se constituem em importantes manuais teórico-metodológicos de fotoetnografia. Tais trabalhos têm influenciado uma geração de pesquisadores, professores, alunos e até mesmo disciplinas são realizadas nessa perspectiva.

Quando digitamos no Google a expressão fotoetnografia, é nítido a quantidade de resultados que aparecem de outras áreas do conhecimento, além da Antropologia, que estão usando essa modalidade de pesquisa, que é ainda recente, pois possui apenas 25 anos, mas que rompeu os limites disciplinares à medida que adquiriu maturidade e robustez. Vemos, portanto, que a fotoetnografia atualmente encontra-se em plena expansão. Desse modo, o professor Achutti, se constitui, indubitavelmente, em uma referência nacional e internacional no campo da antropologia visual.

A proposta teórico-metodológica da fotoetnografia consiste em utilizar a fotografia como forma de narrativa integral (ACHUTTI, 2004a, p. 74), sem a necessidade de textos, seja na forma de legenda, seja com comentários entre uma imagem e outra. De acordo com Achutti e Hassen (2004b, p. 276), o que caracteriza a fotoetnografia é quando o uso da fotografia, em pesquisas etnográficas, deixa de ser meramente ilustrativo e passa a assumir a centralidade da narrativa. Ao usar a imagem como narrativa etnográfica, a fotografia é utilizada como forma de linguagem. Para o autor, a fotoetnografia consiste no "emprego da antropologia visual enquanto um recurso narrativo autônomo na função de convergir significações e informações a respeito de uma dada situação social” (ACHUTTI, 1997, p. 13). O potencial da fotoetnografia está em realizar descrições densas (GEERTZ, 1989), por meio de imagens fotográficas. O que Achutti propõe, portanto, por meio da fotoetnografia, é a utilização de imagens visuais como linguagem, na qual a fotografia recebe a mesma importância que as palavras. Desse modo, o dossiê tem o escopo de comemorar o aniversário desse conceito antropológico, homenagear seu fundador, além de contribuir para pesquisas denominadas estado da arte.

Os artigos reunidos neste dossiê, convidam os leitores da Revista Brasileira de Sociologia da Emoção a adentrar ao campo teórico e metodológico tanto da Fotoetnografia quanto da Sociologia e Antropologia da Imagem. Os manuscritos que os leitores têm em mãos-contribuem para a reflexão sobre o potencial que as imagens visuais possuem para a produção de pesquisa com linguagem e metodologia científica para além das palavras. 
Abrindo o dossiê, temos o artigo Fotoetnografia: 25 anos de autoria do "anfitrião", professor Luiz Eduardo Ribonson Achutti. Nesse texto o autor apresenta na forma de memorial o nascedouro da fototoetnogria, apontando seu contexto multidisciplinar que culminaram nesse conceito amplamente utilizado Antropologia, Sociologia, Educação entre outras áreas.

No estudo Fotoetnografando: modalidades de narrativas imagéticas, Ondina Fachel Leal (orientadora de mestrado do Achutti), Augusto Leal de Britto Velho e Milena Weber Rodrigues abordam algumas modalidades de usos de antropologia visual, que se referem a quatro pesquisas bastante diversas entre si. O argumento dos autores é que os quatro casos apresentam um vínculo entre si que indicam uma linhagem da fotoetnografia, trabalhos nos quais a imagem é tomada como central na narrativa etnográfica.

Em De Árvores, Pedras e Homens - Singularidades da fotografia nas Ciências Sociais, Nuno Godolphim, problematiza algumas das especificidades da fotografia nas ciências sociais e, particularmente, na antropologia visual. Nesse artigo, o autor se propõe a analisar de que maneira uma foto produzida sobre um ser humano é qualitativamente diferente da foto de uma paisagem ou de uma pedra. Para tal, situa as diferentes concepções de sujeito que estão embutidas no olhar do fotógrafo que registra paisagens naturais, paisagens humanas e paisagens culturais.

No artigo Os discursos imagéticos na fotoetonografia: reflexões metodológicas de uma pesquisa com caminhoneiras, Julice Salvagni, Marília Veríssimo Veronese, Renato Koch Colomby e Cibele Cheron abordam as potencialidades da fotoetnografia, a partir de uma experiência de pesquisa realizada com caminhoneiras, no estado do Rio Grande do Sul, entre os anos de 2013 e 2015. Por meio de pesquisa qualitativa os autores problematizam a realidade das caminhoneiras e discutem os aspectos constituintes das suas produções identitárias na relação com gênero e trabalho.

Em Sereias: um estudo fotoetnográfico sobre a mulher na atividade pesqueira no estado do Ceará Fernanda Cunha Oliveira e Geórgia Maria Feitosa e Paiva apresentam um estudo fotoetnográfico sobre o protagonismo feminino nas atividades de pesca no litoral cearense. O referido estudo teve início em 2012, com projeto fotoetnográfico apoiado pelo do Ministério da Cultura, Correios, Secretaria de Cultura do Estado do Ceará SECULT e Local Foto. Ao todo foram visitados sete municípios do litoral cearense conhecidos pela pesca artesanal de mariscos, algas e peixes.

No texto O (re)encontro de Achutti com a Vila Dique, Maíra Brum Rieck e Priscila Chagas Oliveira trazem um testemunho do reencontro de Luiz Eduardo Robinson Achutti e de suas fotografias com a Vila Dique e também com o Museu das Memórias ( $I n$ )Possíveis, que procurou o fotógrafo para justamente musealizar o trabalho realizado por ele na primeira recicladora de materiais recicláveis do Brasil, em Porto Alegre, Rio Grande do Sul. 
No artigo Uma fotoetnografia dos homens da lama: os caranguejeiros do Delta do Parnaiba - PI, Carlos Eduardo de Castro ao discutir a contribuição da fotoetnografia, problematiza a trajetória da antropologia visual no Brasil, desde as gravuras produzidas a partir das narrativas dos cronistas do século XVI ao conceito da fotoetnografia, concebido por Achutti. Em seguida apresenta uma narrativa fotoetnográfica, realizada em 2013, sobre o trabalho dos que nomeamos "homens da lama", que são os catadores de caranguejo da Ilha Grande, no Delta do Parnaíba Piauiense.

Em A revista Fotocronografias e os desafios da construção de periódicos digitais para publicaşão de fotoetnografias, Matheus Cervo aborda as especificidades da construção de periódicos científicos digitais para publicação de fotoetnografias no Brasil. Parte-se da compreensão de que, nas últimas duas décadas, as revistas acadêmicas online foram desenvolvidas principalmente para publicação de artigos científicos escritos, havendo uma lacuna de pesquisa no que se refere às produções universitárias que são feitas com outras mídias - como a fotografia.

No texto História de uma foto e fotos que contam histórias, Ondina Fachel Leal e Luiz Eduardo Robinson Achutti de um lado, fazem uma homenagem a Mauro Guilherme Pinheiro Koury (in memoriam), que soube compartilhar com todos nós seu conhecimento sobre emoções e sobre imagens. De outro, estabelecem um paralelo entre duas sequências de fotos de Achutti. O autor toma dois conjuntos de imagens, ou duas narrativas a respeito de processos de mobilização e protesto de mulheres que ocorrem em um intervalo de mais de três décadas, em contextos históricos distintos, ambos no mesmo cenário, a Casa de Estudantes da UFRGS em Porto Alegre.

No ensaio visual intitulado Projeto bezalel: um ensaio de antropologia visual no bairro sanga funda em cascavel - PR onde Fábio Lopes Alves, Claudia Barcelos de Moura Abreu, Tania Maria Rechia Schroeder, Marco Antonio Batista Carvalho, Adrian Alvarez Estrada e Valdecir Soligo, por meio de um ensaio visual, descrevem parte dos resultados de uma transformação artística que ocorreu no bairro Sanga Funda, em Cascavel - PR, no âmbito do projeto "Bezalel: arte que transforma". A proposta consistiu em colorir o bairro, com a revitalização de algumas residências, por meio de pinturas e arte do graffiti. Para tal, o projeto contou com a participação de diversos artistas, oriundos de diferentes estados do Brasil, na qual todos tinham algo em comum: a ação voluntária.

Encerrando o dossiê temos o texto Animais vivos, feira livre, onde Lucas Barreto de Souza, debate a partir de uma inspiração etnográfica oriunda de uma visita a um setor de animais vivos de uma grande feira livre baiana, a Feira de São Joaquim (anteriormente chamada de Feira de Água de Meninos), aspectos relacionados às epistemologias ecológicas, à TAR (teoria do ator-rede), a agência dos objetos, relações humano-animal, mercados úmidos, biossegurança e sacrifício animal. A discussão está articulada a diversos referenciais bibliográficos, mas a condução do raciocínio está pautada em diálogos com alguns argumentos e exemplos apresentados por Caetano Sordi. 
Paradoxalmente, para que o potencial da narrativa fotográfica encontre solo fértil, é preciso atentar para algo que Mauro Koury, há mais de duas décadas, já nos chamava a atenção, cuja tarefa, apesar de iniciada, ainda tem muito a ser feito até que seja concluída. Nas palavras dele, é necessário: “uma educação, uma pedagogia capaz de ensinar aos homens a lerem, a explorarem os próprios enunciados do real contidos nos recortes revelados pela imagem apreendida e exposta sendo, deste modo, necessária.” (KOURY, 1999, p. 63). Desse modo, este dossiê além de se constituir em uma homenagem ao Luiz Achutti e ao Mauro Koury, também se propõe a contribuir para a essa educação e essa pedagogia sensível a potencialidade das imagens.

\section{REFERÊNCIAS}

ACHUTI, Luiz Eduardo Robinson. Fotoetnografia da Biblioteca Jardim. Porto Alegre: Editora da UFRGS: Tomo Editorial, 2004a.

Fotoetnografia: um estudo de antropologia visual sobre cotidiano, lixo e trabalho.

Porto Alegre: Tomo Editorial, Palmarinca, 1997.

.; HASSEN, Maria de Nazareth Agra. Caderno de campo digital: antropologia em novas mídias. Horizontes Antropológicos. Porto Alegre, v. 10, n. 21, p. 273-289, June 2004b.

ARLAUD, Jean. Prefácio. In: ACHUTTI, L. E. R. Fotoetnografia da biblioteca jardim. Porto Alegre: Editora da UFRGS/Tomo Editorial, p, 17-20, 2004a.

GEERTZ, Clifford. A interpretação das culturas. Rio de Janeiro, Livros Técnicos Científicos, 1989.

KOURY, Mauro Guilherme Pinheiro. Imagem e narrativa - ou, existe um discurso da imagem? Horizontes Antropológicos, Porto Alegre, ano 5, n. 12, p. 59-68, dez. 1999. 